\title{
The Party Wall Casebook
}

\section{Paul Chynoweth}

Blackwell Publishing Ltd, Oxford; 2007: ISBN 978-1-40516324-8; 496pp; $£ 29.50$; paperback

Journal of Building Appraisal (2008) 4, 137. doi:10.1057/jba.2008.24

This publication seeks to enhance the current knowledge of party wall disputes from a legal perspective, by providing the reader with a resource of 80 legal case studies, dating back virtually two centuries. The stated target audience is stated as being the party wall dispute practitioner. It was written to fill a gap in providing legal case studies that relate purely to actions over party walls.

Reviewing this work from the perspective of a surveying practitioner, the reviewer must confess certain confusion about its purpose, perhaps brought about by the book's first line, which refers to the party wall procedure. The reviewer's understanding of the procedure, as laid down by the Party Wall Act (PWA) 1996, is that it was intended to take actions in respect of settling disputed works to party walls away from the County Court and legal precedent, and give the award-making responsibility to the technical decisionmaking skill of the Party Wall Surveyor (PWS). A provision of the act is that the collective decision of the PWSs involved is binding upon both neighbours. The act, however, only deals with its own stated definition of what is a party wall, defines only a limited number of allowable actions, can only be evoked by the issue of a written and timed party wall notice of intention, and has a rigorous time limit, which if exceeded will compromise the outcome. Hence there must be a number of party wall dispute cases, which due to failure to properly commence an action under the PWA, or failure to meet the act's definitions and time limits cannot be settled by the party wall procedure.

Working on the premise of there being significant cases still requiring judgment outside of the PWA procedure the reviewer paid particular attention to those cited cases, which post-dated the implementation of the act, and found that they had indeed not followed the PWA procedure and therefore could not utilise the skill of the PWS in their settlement. On this premise, the book is a highly specialised, well crafted, and organised resource on the relevant case law covering party wall action, outside of the PWA procedure. Its cases are clearly described, and for the described purpose an excellent resource.

While an interesting read for the practising PWS, the reviewer from the perspective of a building appraiser, would caution against its use by non-party wall specialists or by students of surveying and construction. This appears to be a volume written by a practicing solicitor for use by other such lawyers and its use by construction practitioners and building appraisers looking to extend their knowledge of implementing the PWA would be limited.

In summary this is an excellently presented book, with a very specialist legal audience. It appears to have successfully plugged the gap for specialist case law for non-party walls. It requires to be read as a valid legal reference text and with caution by anyone outside of the target legal/party wall specialist audience, particularly by students of construction and surveying, who should perhaps be looking towards learning how to maximise the benefits of using the PWA procedure rather than looking at settlement of non-PWA cases in the courts.

Simon Mclean

Managing Editor 